\title{
Target Production for Inertial Fusion Energy
}

John G. Woodworth

Wayne Meier
RECEIVED

NOV 171995

OSTI

March 1995

This is an informal report intended primarily for internal or limited external distribution. The opinions and conclusions stated are those of the author and may or may not be those of the Laboratory.

Work performed under the auspices of the U.S. Department of Energy by the

Lawrence Livermore National Laboratory under Contract W-7405-Eng-48.

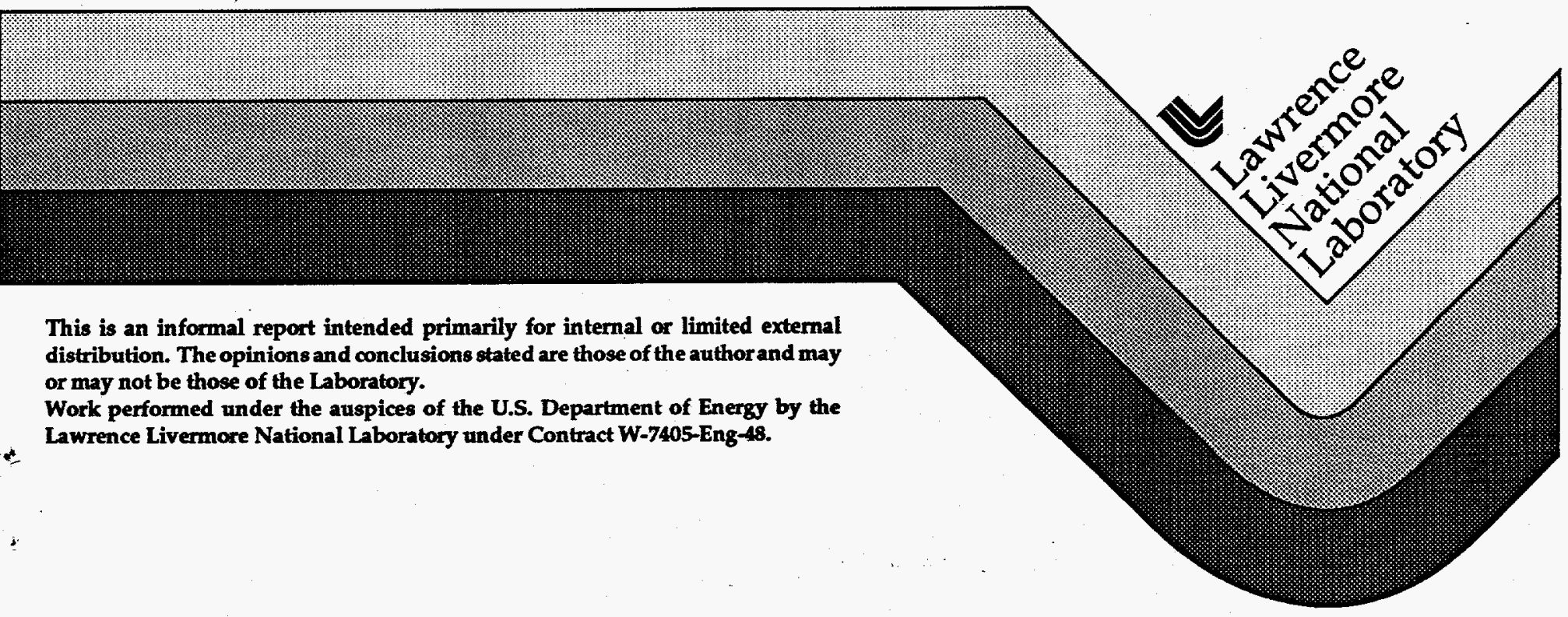




\section{DISCLAIMER}

This document was prepared as an account of work sponsored by an agency of the United States Government. Neither the United States Government nor the University of Califomia nor any of their employees, makes any warranty, express or implied, or assumes any legal liability or responsibility for the accuracy, completeness, or usefulness of any information, apparatus, product, or process disclosed, or represents that its use would not infringe privately owned rights. Reference herein to any specific commercial products, process, or service by trade name, trademark, manufacturer, or otherwise, does not necessarily constitute or imply its endorsement, recommendation, or favoring by the United States Government or the University of California. The views and opinions of authors expressed herein do not necessarily state or reflect those of the United States Government or the University of California, and shall not be used for advertising or product endorsement purposes.

This report has been reproduced directly from the best available copy.

Available to DOE and DOE contractors from the

Office of Scientific and Technical Information
P.O. Box 62, Oak Ridge, TN 37831

Prices available from (615) 576-8401, FTS 626-8401

Available to the public from the

National Technical Information Service

U.S. Department of Commerce

5285 Port Royal Rd.,

Springfield, VA 22161 


\section{DISCLAIMER}

Portions of this document may be illegible electronic image products. Images are produced from the best available original document. 


\section{Target Production for Inertial Fusion Energy}

John G. Woodworth

Lawrence Livermore National Laboratory

Wayne Meier

W. J. Schafer Associates, Inc.

March 1995 


\section{Contents}

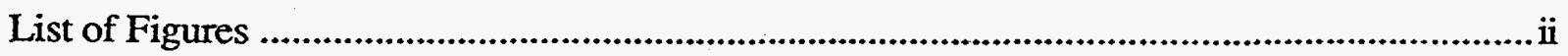

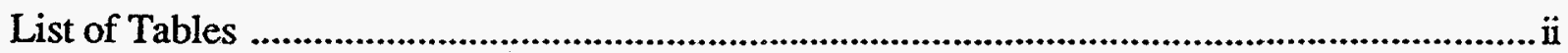

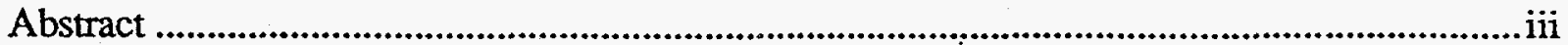

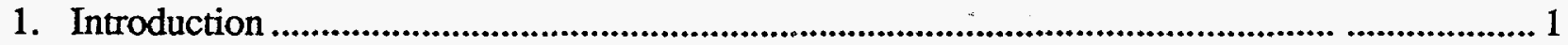

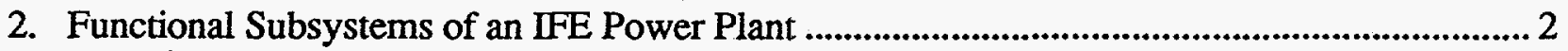

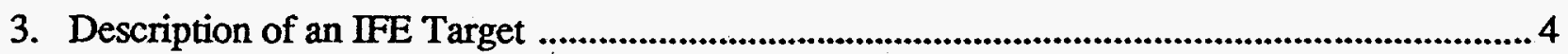

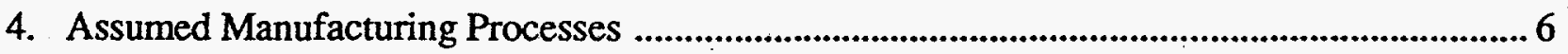

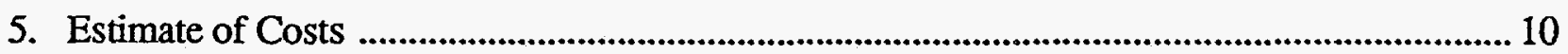

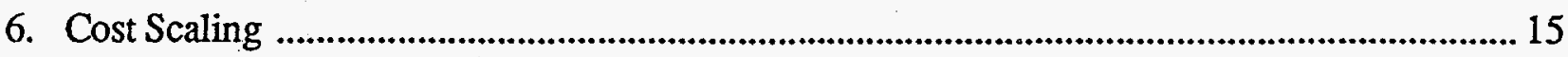

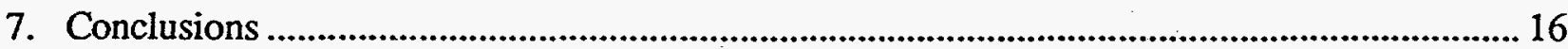

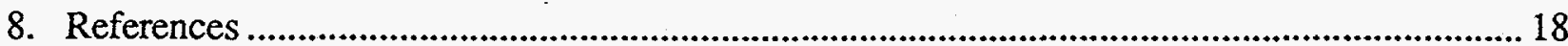




\section{List of Figures}

1. The major subsystems of an IFE power plant ......................................................... 2

2. Reference target design is a indirect-driver target for a heavy-ion driver ........................ 5

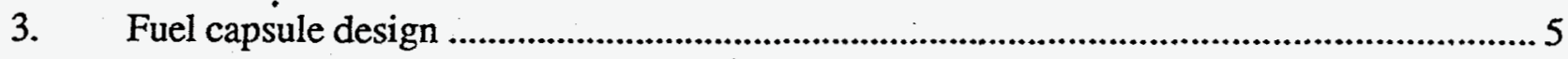

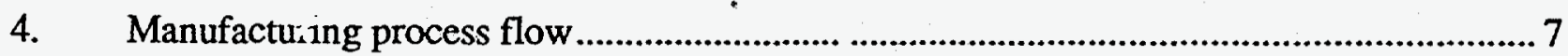

5. Schematic of capsule fabrication process using microencapsulation .............................8

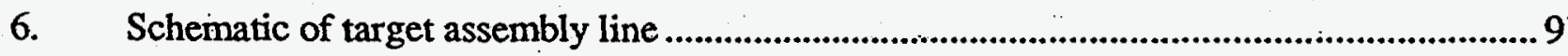

7. Target cost versus rep-rate for different size power plants compared to a goal of $0.5 \phi / \mathrm{kW}_{\mathrm{e}} \mathrm{h}\left(=10 \%\right.$ of the assumed COE of $\left.5 \phi / \mathrm{kW}_{\mathrm{e}} \mathrm{h}\right)$

\section{List of Tables}

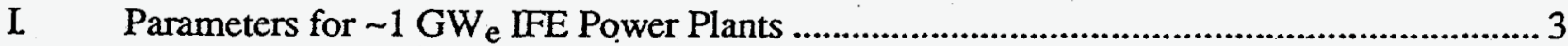

II. Some Indirect Drive Target Design Options.........................................................4

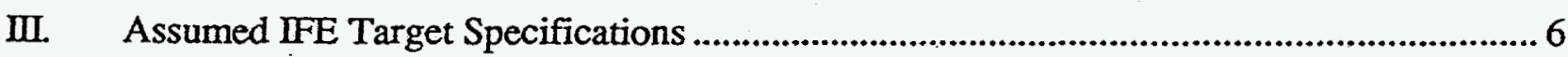

IV. Cost of Materials in Assumed IFE Target ....................................................... 11

V. Cost Formula for Estimating Direct Capital Costs ..................................................... 11

VI. Summary of Target Factory Capital Costs .................................................................. 14

VII. Cost Formula for Estimating Operating Costs ....................................................... 14

VIII. Summary of Target Factory Operating Costs .............................................................. 15

IX. Cost Scaling for Components of Target Factory ..................................................... 16 


\begin{abstract}
Inertial fusion energy (IFE) power plants will require the ignition and burn of 5-10 fusion fuel targets every second. The technology to economically mass produce high-quality, precision targets at this rate is beyond the current state of the art. Techniques that are scalable to high production iates, however, have been identified for all the necessary process steps, and many have been tested in laboratory experiments or are similar to current commercial manufacturing processes. In this paper, we describe a baseline target factory conceptual design and estimate its capital and operating costs. The result is a total production cost of $\sim 16 \varnothing$ per target. At this level, target production represents about $6 \%$ of the estimated cost of electricity from a $1-\mathrm{GW}_{\mathrm{e}} \mathrm{IFE}$ power plant. Cost scaling relationships are presented and used to show the variation in target cost with production rate and plant power level.
\end{abstract}




\section{Introduction}

Nuclear fusion has been proposed as an energy source available some time in the 21 st Century. Studies have shown that it is possible, although not certain, that fusion could provide a limitless, environmentally clean, and inherently safe source of electrical power at costs comparable with other proposed future energy sources such as coal or fission (see Refs. 1-7 for example). An IFE power plant would be composed of four major subsystems: a driver, a target chamber (which includes the first wall, tritium breeding blanket, primary coolant, and structural containment), a thermal-to-electric power conversion system (sometimes referred to as the balance of plant or BOP), and a target production facility referred to as the target factory. This paper addresses the target factory and its implications on cost for IFE-produced energy. We also address some of the environmental and safety issues (e.g., tritium inventory and activation of target materials), but these are not discussed in detail. Previous work on target factory conceptual design and costing can be found in Refs. 8-10 as well as in the power plant design studies described in Refs. 3 and 4. Also, a recent review of target production techniques for IFE is given in Ref. 11 and summarized in Ref. 12.

In this paper, we describe a point design and attempt to be as concrete as possible. Some of the details of IFE targets for power production are unknown, and the details of the processes by which they would be fabricated are not necessarily established. Assumptions need to be made to arrive at a concrete, reviewable target factory model. Nevertheless, we attempt herein to answer the question: "If we designed an IFE target production facility today, what would it look like and what would the uncertainties be?"

To gain perspective on what it would take to make target production economically viable, we assume that electricity in a fusion economy sells for $5 \phi / \mathrm{kW}_{\mathrm{e}} \mathrm{h}$ (constant 1990 dollars). The yearly income for a $1-\mathrm{GW}_{\mathrm{e}}$ power plant with $70 \%$ availability would then be $\$ 307 \mathrm{M}$. If we assume a fueling cost goal of $10 \%$ of income, then we allow ourselves $\$ 31 \mathrm{M} / \mathrm{yr}$ to service the cost of money for the initial capital outlay, for target materials, production, redundancy, quality assurance and control, maintenance, delivery, and safety. A typical reactor will require 5 targets/second, or $1.1 \times 10^{8}$ target/yr, corresponding to an income of $\$ 2.80 /$ target and a cost goal of $\sim 30 \not /$ target. The main purpose of this paper is to discuss whether this total cost of $\sim 30 \phi /$ target at a $5-\mathrm{Hz}$ production rate can be reasonably achieved.

Choosing a concrete design for a target production model allows us to define costs better and to study other aspects of target production. Environmental issues can be studied since radioactive and toxic inventories are well defined within the model. A development path can be established since assumptions in the proposed design are glaringly revealed. Most importantly, a concrete model is reviewable. Conversely, detailed designs may underestimate the cost since 
some aspects may be accidentally omitted. And, proposing concrete designs so early in the game makes the conclusions vulnerable to possible incorrect assumptions on which the model is based.

Below, Section 2 describes the relevant features of an IFE power plant. Section 3 describes the representative IFE target we have assumed for IFE power production. Section 4 describes the processes and steps by which this target would be made. Section 5 estimates costs-both capital and operating - and Section 6 examines how costs scale with plant power and target production rate.

\section{Functional Subsystems of an IFE Power Plant}

As previously noted, conceptual IFE power plant designs can be divided into four major subsystems: a driver, a target chamber, a power conversion system, and a target factory. It is an advantage of IFE that these subsystems, shown in Figure 1, are largely independent of each other. The details of the IFE tårget do depend upon the type of driver employed (laser, light-ion, or heavy-ion), the illumination geometry (direct or indirect drive), and the chamber conditions, and these aspects will now be described. Complete descriptions of IFE power plants can be found elsewhere. ${ }^{1-7}$

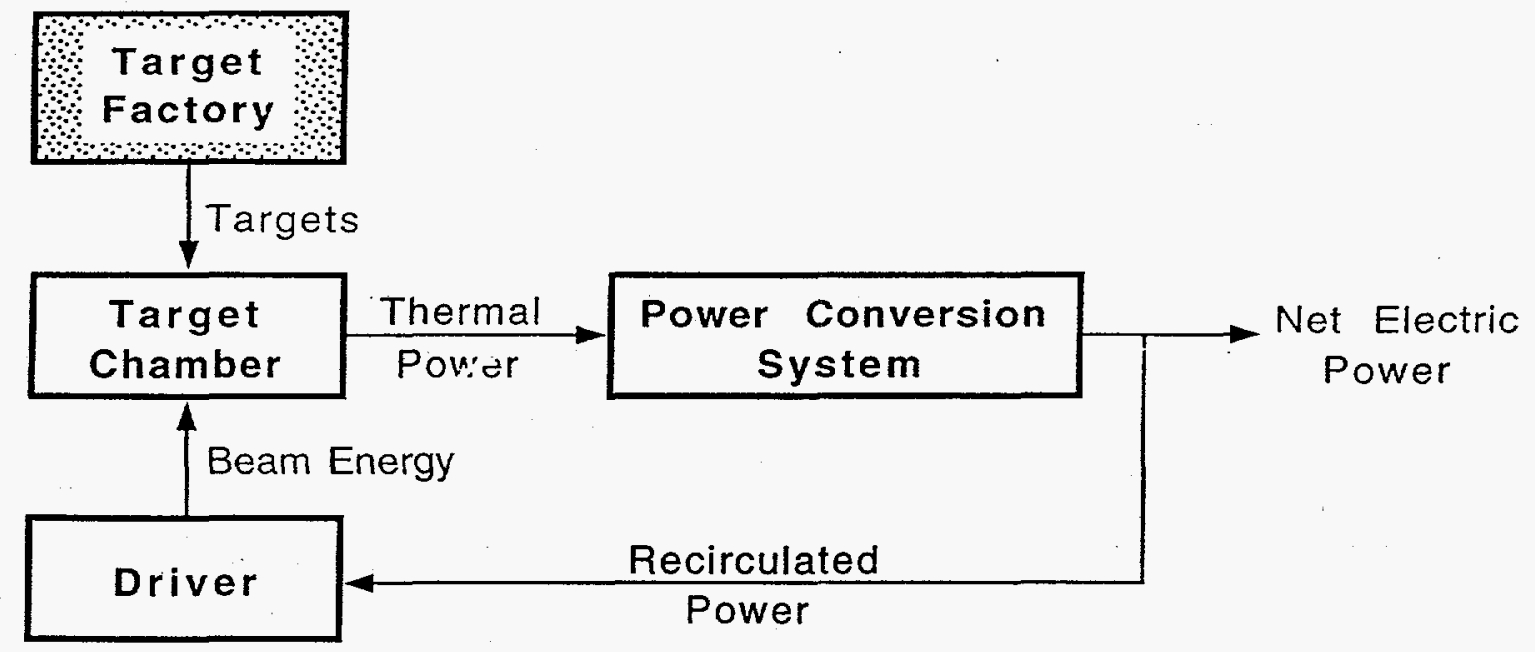

Figure 1. The major subsystems of an IFE power plant.

As indicated in Table I, our baseline parameters are a 5-MJ heavy-ion driver, an indirectdrive illumination target with a yield of $400 \mathrm{MJ}$, and a target chamber operating at $5 \mathrm{~Hz}$. These values are consistent with published heavy-ion power plant conceptual design studies ${ }^{1-5}$ also listed in Table I. In addition, the baseline target parameters are consistent with the heavy ion target design described in Ref. 13, which has a gain of 80 and yield of $430 \mathrm{MJ}$. 


\section{Table I. Parameters for $\sim 1$ GW IFE Power Plants}

\begin{tabular}{|l|c|c|c|c|}
\hline $\begin{array}{c}\text { Power } \\
\text { Plant }\end{array}$ & $\begin{array}{c}\text { Driver Energy } \\
\text { (MJ) }\end{array}$ & $\begin{array}{c}\text { Target } \\
\text { Gain }\end{array}$ & $\begin{array}{c}\text { Yield } \\
\text { (MJ) }\end{array}$ & $\begin{array}{c}\text { Rep-rate } \\
\text { (Hz) }\end{array}$ \\
\hline $\begin{array}{l}\text { Baseline for } \\
\text { this study }\end{array}$ & 5 & 80 & 400 & 5 \\
\hline Cascade & 5 & 75 & 375 & 5 \\
\hline HYLIFE-II & 5 & 70 & 350 & 6 \\
\hline Osiris & 5 & 87 & 432 & 4.6 \\
\hline Prometheus & 7 & 103 & 720 & 3.5 \\
\hline HIBALL-II & 5 & 80 & 400 & 5 \\
\hline
\end{tabular}

In such a power plant, a heavy ion driver allows double-sided illumination (as opposed to multi-sided illumination for direct-drive lasers) and eliminates the need for holes in the hohlraum since heavy ions deposit their energy volumetrically in the radiators located on the ends of the essentially cylindrical-shaped hohlraum (see Figure 2). An IFE target chamber is expected to operate with an interior ambient temperature of $\sim 1000 \mathrm{~K}$ to achieve good thermodynamic efficiency converting heat to electricity. At these temperatures, a bare cryogenic capsule would be damaged during transit to the center of the chamber. The hohlraum, however, protects the capsule from the thermal radiation. (A removable sabot or other protective covering is needed to protect direct drive targets.)

Another aspect of the chamber and driver that affects target production is the pulse repetition rate. A given fusion power level can be delivered by a few large fusion yields per second or by a greater number of smaller yields per second. Rapid firing of smaller yields eases the peak stresses on the chamber, but the time available for chamber clearing becomes shorter so that limitations occur because of vacuum requirements dictated by driver beam propagation in the chamber. The target gain also drops off at lower driver energies leading to higher recirculating power and giving the system too low an efficiency. From the target fabrication viewpoint, high-gain targets for low driver energies require greater precision. Thus, we have chosen middle-of-the-road baseline plant parameters and will attempt to scale the target production costs to other regions of parameter space. 


\section{Description of an IFE Target}

A heavy ion target design has been chosen as a baseline. We anticipate that this target has all the features relevant to target fabrication for commercial IFE power some 30-50 years hence. A schematic representation of the baseline target is shown in Figures 2 and 3. The basic geometry is that given by Ref. 13, but we changed some of the materials based on manufacturability, recycling, and safety considerations (e.g., we postulate a polystyrene $\left[\mathrm{C}_{2} \mathrm{H}_{3}\left(\mathrm{C}_{6} \mathrm{H}_{5}\right)\right]_{\mathrm{n}}$ fuel capsule instead of $\left.\mathrm{Be}\right)$. Certainly, other material choices might be made based on the particular reactor design, but those used here will allow us to define the required production processes and estimate the costs. Table II lists the baseline target characteristics along with some alternative options that have been proposed. References 11 and 12 discuss the advantages and disadvantages of various options for capsule production, DT-fill, and cryogenic layering processes.

Table II. Some Indirect Drive Target Design Options

\begin{tabular}{|c|c|c|c|c|c|}
\hline $\begin{array}{c}\text { Design } \\
\text { Case }\end{array}$ & $\begin{array}{c}\text { Capsule } \\
\text { Material }\end{array}$ & $\begin{array}{c}\text { Separate } \\
\text { Ablator? }\end{array}$ & $\begin{array}{c}\text { Hohlraum } \\
\text { Material }\end{array}$ & $\begin{array}{c}\text { Hohlraum } \\
\text { Lining }\end{array}$ & $\begin{array}{c}\text { Separate } \\
\text { Sabot? }\end{array}$ \\
\hline Reference & Polystyrene & No & Acetate & $\mathrm{Pb}$ & No \\
\hline Options & $\mathrm{Be}$, Glass & Yes & $\mathrm{Pb}, \mathrm{Flibe}, \mathrm{Li}$ & $\mathrm{Ta}, \mathrm{Hg}$ & Yes \\
\hline
\end{tabular}

One of the target material selection considerations is neutron activation. On each shot, the unburned fuel, capsule, hohlraum, and radiation conversion materials are vaporized. Depending on the chamber design, these materials are recovered in the vacuum pumping system and/or first wall coolant/protectant. The high- $Z$ lining of the hohlraum is an activation hazard and must be recycled to avoid the production of large quantities of activated material. Even at only $0.3 \mathrm{~g}$ per target, the annual throughput at $5 \mathrm{~Hz}$ is $\sim 33$ tonne. In the Osiris and HYLIFE-II studies, the total inventory of high- $Z$ target material is kept to $<1$ tonne by continuously recycling one week's worth of material. One week is enough time to allow the short-lived radionuclides to decay, making the handling in the hohlraum fabrication process easier.

The reference target is comprised of a fuel capsule suspended by a pair of thin mylar sheets in the center of a hohlraum. The capsule is a $0.22-\mathrm{mm}$-thick, 4.64-mm outer-diameter polystyrene spherical shell that contains a $0.32-\mathrm{mm}$-thick layer of solid DT $(\sim 4 \mathrm{mg})$. (See Figure 3.) We assume that the hohlraum is made out of plastic ( $1 \mathrm{~mm}$ thick) and lined with a 


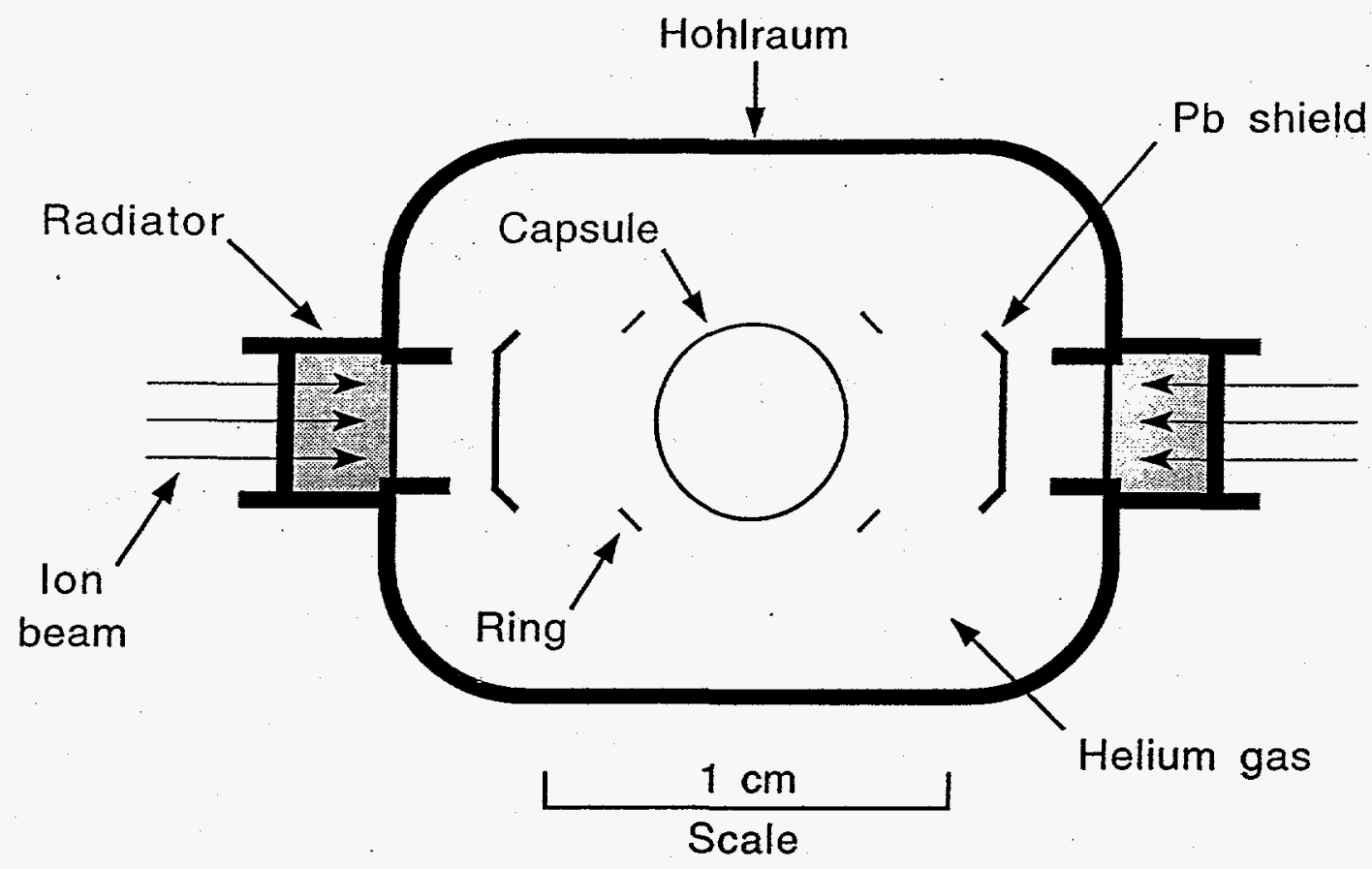

Figure 2. Reference target design is an indirect-driver target for a heavy-ion driver.

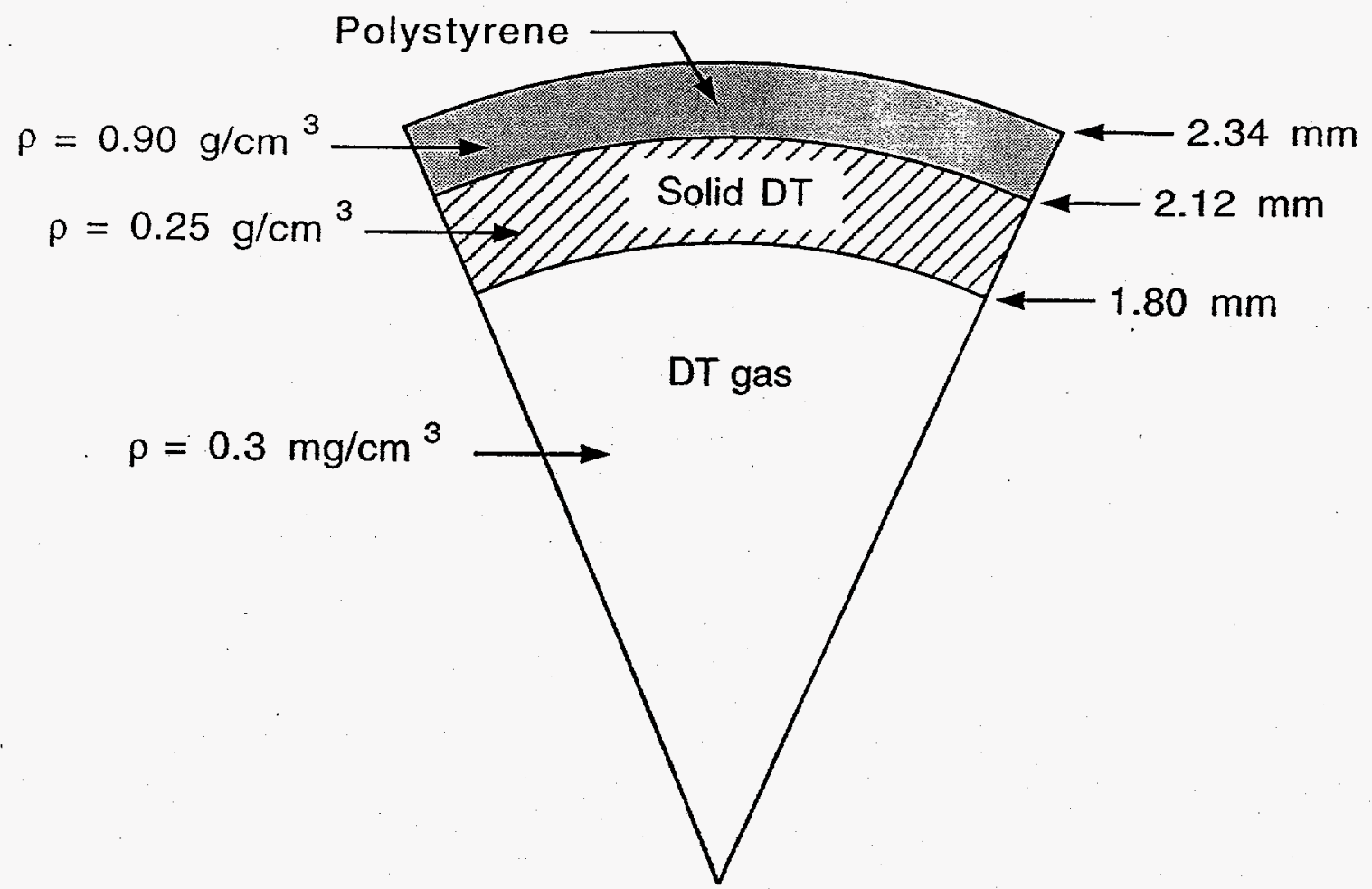

Figure 3. Fuel capsule design. 
thin $(\sim 25 \mu \mathrm{m})$ layer of $\mathrm{Pb}$ for soft $\mathrm{x}$-ray containment and symmetrization. The driver beams are focused at the radiation converters (or radiators) on each end of the hohlraum. The radiators are made of a low- $Z$ material (e.g., plastic) doped with a small amount of high- $Z$ material (e.g., $\mathrm{Pb}$ ). When irradiated, this material heats up and converts the heavy ions' kinetic energy into soft $x$-ray radiation, which fills the hohlraum and irradiates the fuel capsule. Disk-shaped and ring-shaped $\mathrm{Pb}$ shields are used to prevent non-symmetric heating of the capsule. These shields would also be suspended with mylar sheets and could be attached in the hohlraum assembly stage (discussed in the next section) prior to mating with the cryogenic fuel capsule.

The specifications for this target are given in Table III. The hohlraum is $-12 \mathrm{~mm}$ in diameter and $20 \mathrm{~mm}$ long, roughly the diameter of an AA battery (pen light size), but only $40 \%$ as long. The hohlraum is a relatively crude part; it does not require a smooth surface finish or precise manufacture and assembly. The most stressing criterion for the hohlraum assembly is that the fuel capsule be located inside the hohlraum accurately enough to assure symmetric illumination by the soft $\mathrm{x}$ rays.

Table III. Assumed IFE Target Specifications

\begin{tabular}{|c|c|c|c|c|}
\hline Part & Material & $\begin{array}{c}\text { Inner } \\
\text { Diameter } \\
(\mathbf{c m})\end{array}$ & $\begin{array}{c}\text { Thickness } \\
(\mathbf{c m})\end{array}$ & $\begin{array}{c}\text { Required } \\
\text { Accuracy } \\
(\mathbf{c m})\end{array}$ \\
\hline Fuel & Solid DT & 0.360 & 0.021 & $<10^{-5}$ \\
\hline Capsule & Polystyrene & 0.424 & 0.022 & $<10^{-5}$ \\
\hline Hohlraum & Acetate & $\sim 1.2$ & 0.1 & $<10^{-2}$ \\
\hline
\end{tabular}

The tolerances on both the fuel layer and capsule, which is also an ablator, are exacting. Roughness in the surface finish of these layers seeds hydrodynamic instabilities, which can grow during the compression phase characteristic of IFE capsule implosions. The smoothness requirements for these layers are based on calculated growth factors and on the maximum surface fluctuations allowed before significant quenching of the fusion burn occurs due to turbulent mix.

\section{Assumed Manufacturing Processes}

The flow of the manufacturing process is shown in Figure 4. This diagram shows two important features. First, it shows that manufacture of the DT-filled capsule and the hohlraum are in parallel-the two come together during final assembly. Second, it shows two important interfaces: the tritium interface within which this radioactive element of hydrogen is handled and 
the cryogenic interface for manufacturing at temperatures below $18 \mathrm{~K}$. The combination of highvolume production, radioactivity, and cryogenics is unprecedented in mass production and represents a significant developmental challenge for IFE target manufacture.

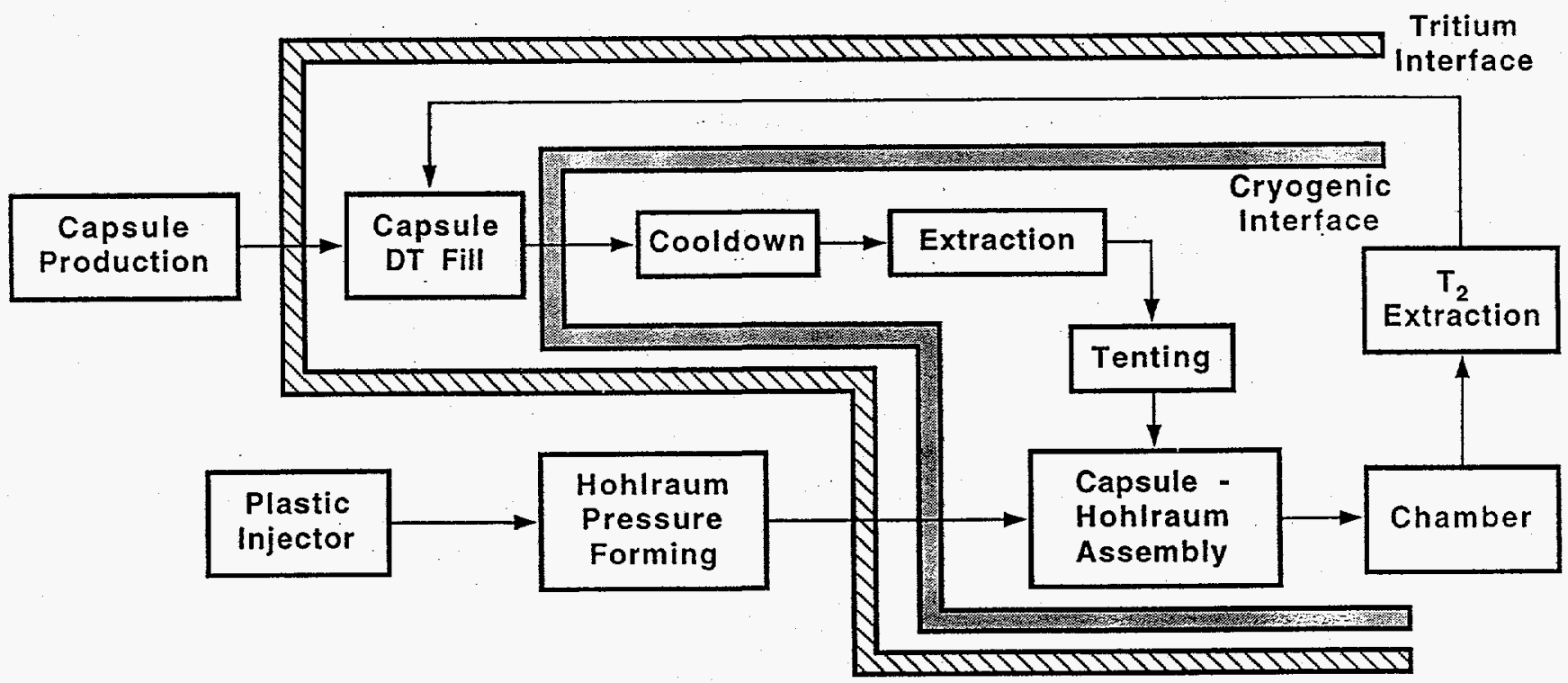

Figure 4. Manufacturing process flow.

The process steps are now discussed in more detail. The capsule production step produces the precision polystyrene capsules. We have chosen to model their manufacture using an extrapolation of the microencapsulation technique. ${ }^{14}$ A schematic representation of this is shown in Figure 5. Using the microencapsulation technique, shells of polystyrene are formed by injecting a liquid layer of polystyrene, sandwiched between two aqueous layers, into a water bath through cylindrical, triply concentric nozzles. These spherical shells are swept out of the column, and the solvent and water are removed. It has been shown that very smooth, spherical shells can be mass produced by this technique, although reactor-sized shells have not been demonstrated. We assume that this process can be scaled to the required production rates, sizes, and quality by implementing the above scheme. The fabricated capsules would undergo inspection and be placed in canisters in order to be filled with DT fuel and cooled down. 


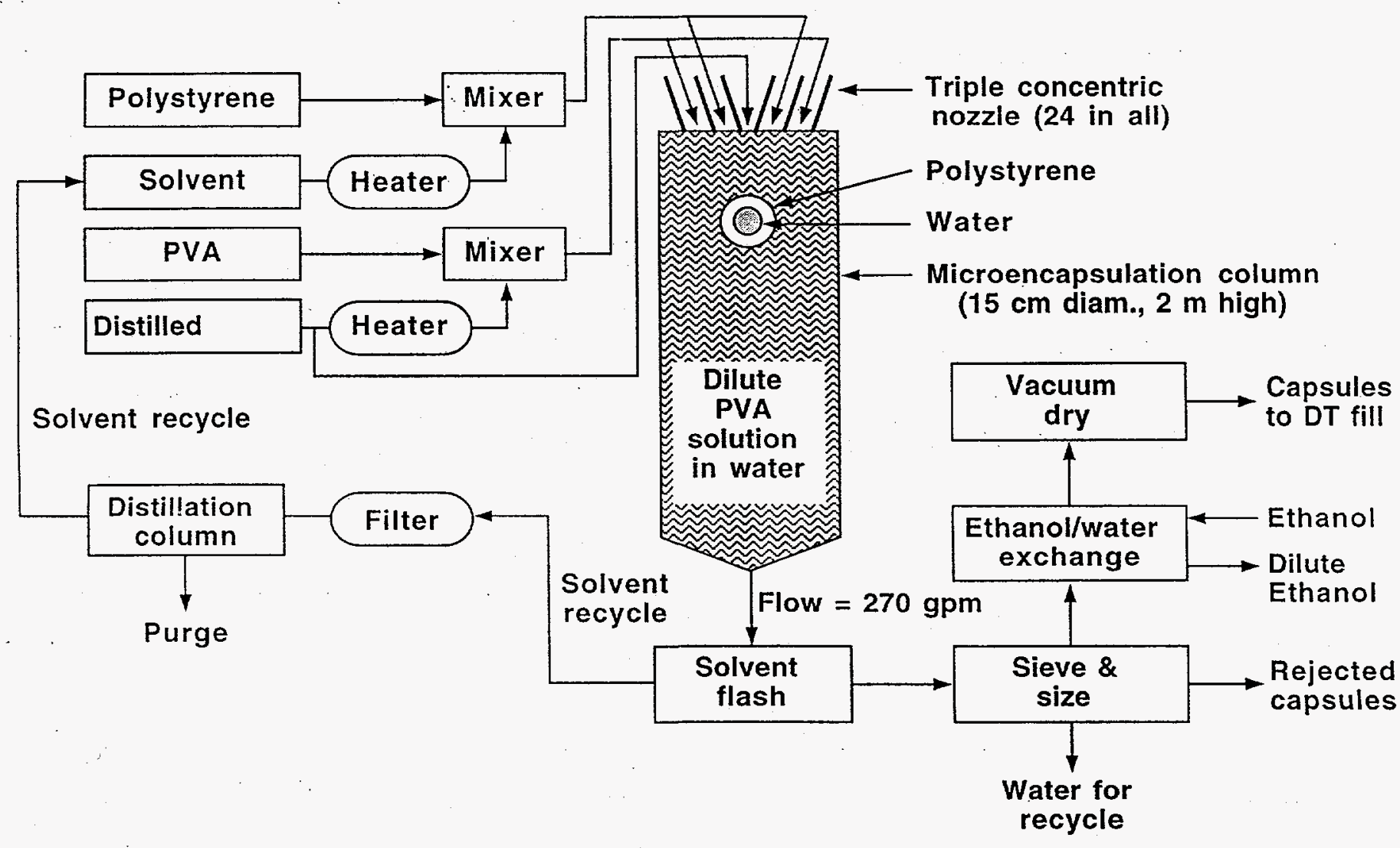

Figure 5. Schematic of capsule fabrication process using microencapsulation.

The fill, cooldown, and "tenting" procedures are shown in Figure 6. The most viable fill method is to diffuse DT gas into the capsule through the polystyrene shell. Quicker methods, such as "drill and plug," may result in intolerable roughness to the capsule's surface. Assuming a 200-atm maximum pressure differential across the shell, we estimate that $40 \mathrm{~h}$ are required to fill the capsule. The tritium inventory demanded by this step at an IFE power plant site is discussed below.

After filling, the capsules are cooled down to just below the triple point of DT (about $18 \mathrm{~K}$ ) so that the capsules are now depressurized. The DT freezes uniformly onto the inside of the polystyrene capsule via the process known as B-layering, ${ }^{15}$ which is assumed to require about 30 minutes. The $B$-layering process has yet to be demonstrated for low-conductivity capsules. 


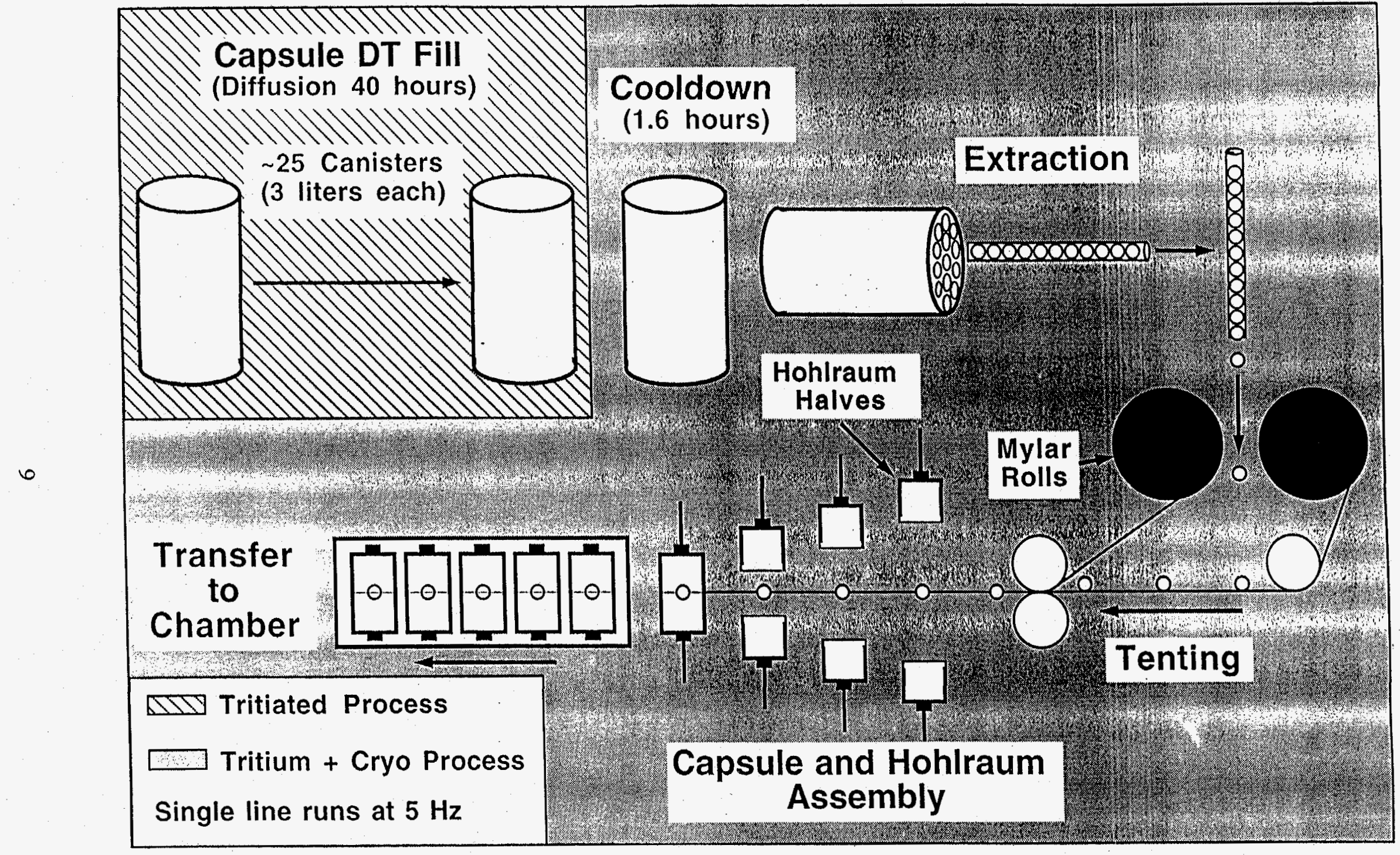

Figure 6. Schematic of target assembly line. 
Meanwhile, the plastic hohlraums can be manufactured cost-effectively using continuous vacuum forming, which is an existing technology. Hohlraum halves would be molded out of acetate sheets that are coated on the inside with a thin layer of $\mathrm{Pb}$. Thin mylar film would be stretched across the opening of each half and the capsule trapped inside the tent formed by the two films when the two halves were snapped together. A conceptual way to implement this is shown in Figure 6. If the radiation smoothing shields shown in Figure 2 are required, each hohlraum half would be constructed of three parts with layers of mylar imprinted with the $\mathrm{Pb}$ shields attached. ${ }^{16}$ Not shown in this schematic is the step needed to insert a radiator plug into the end of each hohlraum half.

Modern production lines use commercially available machinery to carry out automated tasks such as those described here. Examples include production of microelectronics components, pharmaceuticals, golf balls (where at least one brand uses cryogenics in the production process and $\mathrm{x}$-ray diagnostics for quality control), and razor cartridges (where plastics and metals are combined in a high precision assembly process). In the next section we will establish costs for the IFE target assembly line based on present-day equipment.

\section{Estimate of Costs}

In this section we estimate the cost of the materials in each target, the capital cost of the target factory, and the operating and maintenance costs for target production. These costs are combined to calculate the cost per target. All costs are given in 1990 dollars, the year that the estimates were originally made.

\section{Cost of Materials}

As shown in Table IV, the cost of materials is $<1 \phi /$ target and thus is not a large contributor to the overall cost of target production. Note that this cost does not take into account losses of material during production, but these are expected to be small.

\section{Capital Costs}

The capital cost of the target factory can be estimated using standard chemical engineering methods. In the cost-estimating formula given in Table $\mathrm{V}$, the total capital cost of the system is derived from an estimate of the purchased equipment cost (PEC). ${ }^{17}$ The items listed in Table $\mathrm{V}$ include everything needed to install and operate the actual process equipment. As indicated, the total direct cost is $3.3 \times \mathrm{PEC}$, and the total capital investment (TCI), which includes engineering costs and working capital (i.e., interest during construction), is $6.3 \times \mathrm{PEC}$. 
Table IV. Cost of Materials in Assumed IFE Target (1990 dollars)

\begin{tabular}{|l|l|c|c|c|c|c|c|}
\hline Target Part & Material & $\begin{array}{c}\text { Density } \\
\left(\mathbf{g} / \mathbf{c m}^{3}\right)\end{array}$ & $\begin{array}{c}\text { Thickness } \\
(\mathbf{m m})\end{array}$ & $\begin{array}{c}\text { Volume } \\
\left(\mathbf{c m}^{\mathbf{3}}\right)\end{array}$ & $\begin{array}{c}\text { Mass } \\
(\mathbf{g})\end{array}$ & $\begin{array}{c}\text { Specific } \\
\text { Cost } \\
(\mathbf{c} / \mathbf{g})\end{array}$ & $\begin{array}{c}\text { Cost per } \\
\text { Target } \\
(\mathbf{\ell})\end{array}$ \\
\hline Fuel & Solid DT & 0.25 & 0.32 & 0.016 & 0.004 & 4.8 & 0.02 \\
\hline Capsule & Polystyrene & 0.90 & 0.22 & 0.014 & 0.012 & 0.4 & 0.005 \\
\hline $\begin{array}{l}\text { Hohlraum } \\
\text { Lining }\end{array}$ & Lead & 11.3 & 0.025 & 0.025 & 0.28 & 0.3 & 0.08 \\
\hline $\begin{array}{l}\text { Hohlraum } \\
\text { Membrane }\end{array}$ & Acetate & 0.90 & 1.0 & 1.0 & 0.90 & 0.4 & 0.36 \\
\hline Mylar & 0.90 & $10^{-4}$ & $5 \times 10^{-5}$ & $5 \times 10^{-5}$ & 0.4 & $2 \times 10^{-5}$ \\
\hline
\end{tabular}

Table V. Cost Formula for Estimating Direct Capital Costs (Ref. 17)

\begin{tabular}{|l|c|}
\hline Capital Cost & Fraction of PEC \\
\hline Direct Costs & 1.00 \\
Purchase Equipment Cost (PEC) & 0.40 \\
Equipment Installation & 0.02 \\
Insulation & 0.20 \\
Instrumentation \& Control & 0.30 \\
Piping, Valves, etc. & 0.15 \\
Electrical Installation & 0.47 \\
Buildings and Services & 0.55 \\
Service Facility & 0.12 \\
Yard Improvements & 0.16 \\
Land & $\mathbf{3 . 3 ~ P E C ~}$ \\
Total Direct Costs (TDC) & \\
\hline Indirect Costs & 1.15 \\
Engineering \& Supervision (35\% TDC) & 0.33 \\
Construction Expenses (10\% TDC) & 0.17 \\
Contractor Fees (5\% TDC) & 0.33 \\
Contingency (10\% TDC) & $\mathbf{2 . 0 ~ P E C ~}$ \\
Total Indirect Costs (TIC) & $\mathbf{1 . 0 ~ P E C ~}$ \\
\hline Working Capital = 0.18 (TDC + TIC) & $\mathbf{6 . 3 ~ P E C ~}$ \\
\hline Total Capital Investment (TCI) & \\
\hline
\end{tabular}


Capsule Production. By specifying the capsule size and the chamber pulse repetition rate, material flow rates are established, and the size of the equipment required to implement the microencapsulation process in mass production is estimated. The PEC for the capsule fabrication subsystem, based on the design and costing of the equipment shown in Figure 4, is $\$ 10 \mathrm{M}$. Adding the other costs listed in Table $\mathrm{V}$ gives a total direct cost of $\$ 33 \mathrm{M}$ and a total capital investment for this subsystem of $\$ 63 \mathrm{M}$.

Hohlraum Production and Assembly. The costs of producing the hohlraum can be estimated with considerable certainty. This part can be manufactured with equipment and materials currently available on existing production lines. A production line based on a model 2530BT continuous vacuum-forming machine from John Brown Plastics Machinery Division of Brown Machines could be used to produce hohlraums at a rate of 6 to 8 per second. ${ }^{18} \mathrm{An}$ automated line to stamp hohlraums from acetate sheets laminated with a veneer of $\mathrm{Pb}$ on the interior, apply the mylar tenting, and perform the final assembly has been estimated to cost about $\$ 250 \mathrm{~K}$ by that manufacturer. ${ }^{18}$ We allow an additional $\$ 150 \mathrm{~K}$ for the equipment needed to manufacture and insert the radiation conversion plugs. This gives an estimated PEC of $\$ 400 \mathrm{~K}$ for this subsystem. Since the cost of hohlraum production is small compared to capsule production, variations in hohlraum design are not expected to significantly impact the cost of targets.

DT Fill. We first estimate the factors in the fill process that drive cost and safety in a substantial way. A $1-G W_{e}$ fusion plant with the baseline parameters of Table I burns tritium at $\sim 13 \mathrm{~g} / \mathrm{h}$. Only about $30 \%$ of the capsule fuel is burned during each pulse, so $42 \mathrm{~g} / \mathrm{h}$ of tritium must actually be supplied to the reactor. Each capsule contains $\sim 2.3 \mathrm{mg}$ of tritium (in $3.9 \mathrm{mg}$ of DT). The unburned fuel is recycled to the target factory. As discussed in Section 4 , about $40 \mathrm{~h}$ are required to diffuse the DT fuel into a capsule. Thus, a large inventory $\left(7.2 \times 10^{5}\right.$, corresponding to a $40-\mathrm{h}$ supply) of capsules in various stages of fill is required. On the average, the capsules are half full so that about $0.5 \times 42 \mathrm{~g} / \mathrm{h} \times 40 \mathrm{~h}=0.84 \mathrm{~kg}$ of tritium is contained within capsules in the fill stage of the target factory at any given time. As indicated in Figure 6, the targets are pressurized in batches using 25 separate canisters. Assuming a capsule packing fraction of $50 \%$, the interior volume of each canister is $\sim 3$ liters. Accounting for the volume occupied by the plastic shell, we estimate the canisters contain $1.14 \mathrm{~kg}$ of tritium in the open space between capsules (averaged over the 40-h fill cycle) giving a total of $2 \mathrm{~kg}$ in the 25 capsule-filled canisters. We increase this estimated tritium mass by a factor of two (i.e., to $4 \mathrm{~kg}$ ) to allow for tritium in the fill system plumbing, filled capsules in the cooldown, extraction, hohlraum mating process steps, and completed targets that are stored to provide a backup inventory to keep the plant running in the event of a short shutdown of the target production facility. 
Each of the 25 canisters is a small pressure vessel. Segmenting the tritium fill process in this manner has at least three benefits: (1) it reduces the total tritium inventory compared to filling a single $40-\mathrm{h}$ batch of targets, (2) it segments the tritium inventory so that the amount at risk from the failure of any one canister is much less than the failure of a single large pressure vessel, and (3) it allows the batch-mode fill process to more closely approximate the continuous flow of targets that must be provided to the target chamber. Each canister has an interior volume of $\sim 3$ liters. We estimate the PEC, built to nuclear industry safety standards, to be $\$ 400 \mathrm{~K}$ for 25 canisters.

Robotics. Every $1.6 \mathrm{~h}$ a canister completes the DT fill step and is moved to a cooldown station. At the same time, the canister in the cooldown station is removed, and the capsules are extracted to feed the capsule/hohlraum mating process (see Figure 6). Robotics will be needed to perform these and other transfer operations in the target production process. We estimate a PEC of $\$ 2.0 \mathrm{M}$ for robotics.

Cryogenics. As previously noted, the 25 canisters would be at various stages within the fill cycle, and every $1.6 \mathrm{~h}$ a canister completes its fill and commences cooldown to $\sim 18 \mathrm{~K}$. There are $1.6 \mathrm{~h}$ between the end of cooldown and injection into the reactor during which B-layering symmetrizes the DT fuel. (Just prior to injection into the reactor, it may be necessary to cool the targets further to $4 \mathrm{~K}$ in order to survive traversal of the hot reactor vessel. This step is not considered in this paper.) The cooldown cycle will require $-2 \mathrm{~kW}$ of cooling power plus an interface between the high-pressure fill system and the cryogenic assembly line. The PEC of the cryogenic system is estimated at $\$ 600 \mathrm{~K}$.

Building Premium. The minimum floor area occupied by the target production equipment is not large: $-2-3 \mathrm{~m}^{2}$ for the fill system and cooldown steps and $\sim 10 \mathrm{~m}^{2}$ for the assembly line. Allowing for support equipment, access space, controls, etc., might result in a building as large a $100 \mathrm{~m}^{2}$, which is about half the size of the target fabrication building at LLNL. Building costs are included in the cost estimating formula given in Table V. Based on the sum of the PECs discussed above, the building and services item of Table $V$ would have a direct capital cost of $\$ 6.3 \mathrm{M}$. However, since the target factory must be designed to handle radioactive material, we also assume that this building is constructed to nuclear industry safety standards, and we add a premium of $\$ 3 \mathrm{M}$ direct cost (nearly $50 \%$ ). The total direct cost for the building at $\$ 9.3 \mathrm{M}$ is $\$ 93,000 / \mathrm{m}^{2}\left(\$ 8600 / \mathrm{ft}^{2}\right)$. The $\$ 9.3 \mathrm{M}$ is roughly consistent with the $\sim \$ 7 \mathrm{M}$ cost estimate made by Bechtel for the target factory buildings for the Osiris and SOMBRERO IFE power plants. ${ }^{3}$

A summary of the capital cost components described above is given in Table VI. 
Table VI. Summary of Target Factory Capital Costs (1990 dollars)

\begin{tabular}{|l|c|c|c|}
\hline \multicolumn{1}{|c|}{ Production Process } & $\begin{array}{c}\text { Purchase } \\
\text { Equip. Cost } \\
\mathbf{( \$ \mathbf { M } )}\end{array}$ & $\begin{array}{c}\text { Direct } \\
\text { Cost } \\
\mathbf{( \$ \mathbf { M } )}\end{array}$ & $\begin{array}{c}\text { Total Capital } \\
\text { Investment } \\
\mathbf{( \$ \mathbf { M } )}\end{array}$ \\
\hline Capsuls Production & 10 & 33 & 63 \\
Hohlraum Production and Assembly & 0.4 & 1.3 & 2.5 \\
DT Fill & 0.4 & 1.3 & 2.5 \\
Robotics & 2.0 & 6.6 & 12.6 \\
Cryogenics & 0.6 & 2.0 & 3.8 \\
Building Premium for N-stamp & - & 3.0 & 5.7 \\
\hline Total & $\mathbf{\$ 1 3 . 4} \mathbf{M}$ & $\mathbf{\$ 4 7} \mathbf{M}$ & $\mathbf{\$ 9 0} \mathbf{M}$ \\
\hline
\end{tabular}

\section{Operating and Maintenance Costs}

The annual operating and maintenance (O\&M) costs for the target factory have been estimated using the formula shown in Table VII. The operating costs include an allowance for manpower (which is proportional to the number of workers), insurance, overhead, and maintenance (all of which are proportional to the capital investment), and an estimate for supplies and expenses related to O\&M operations.

Table VII. Cost Formula for Estimating Operating Costs (Ref. 17)

\begin{tabular}{|l|c|}
\hline Operating Cost & Amount (\$M) \\
\hline Manpower (\$150K per FTE*) & $0.15 \mathrm{FTE}$ \\
Insurance (1\% Capital Investment) & $0.06 \mathrm{PEC}$ \\
Overhead (1.5\% Capital Investment) & $0.09 \mathrm{PEC}$ \\
Maintenance (4\% Capital Investment) & $0.25 \mathrm{PEC}$ \\
Supplies \& Expenses (estimated) & S\&E \\
\hline Total Annual Operating Costs & $\mathbf{0 . 1 5}$ FTE + 0.41 PEC + S\&E \\
\hline
\end{tabular}

* FTE $=$ Full-Time Employee

The resulting O\&M cost estimate for the reference case design is given in Table VIII. Assuming a staff of five operators and three shifts, gives 15 FTEs for the target factory. The insurance, overhead, and maintenance costs are based on the total capital investment of $\$ 90 \mathrm{M}$ 
given in Table VI. Supplies and expenses are estimated at $\$ 2 \mathrm{M}$ per year. The total annual O\&M cost is $\$ 9.1 \mathrm{M}$, or about $10 \%$ of the total capital investment.

Table VIII. Summary of Target Factory Operating Costs (1990 dollars)

\begin{tabular}{|l|c|}
\hline Operating Cost & Amount (\$M) \\
\hline Manpower & 2.25 \\
Insurance & 0.90 \\
Overhead & 1.35 \\
Maintenance & 3.60 \\
Supplies \& Expenses & 1.00 \\
\hline Total Annual Operating Costs & $\$ 9.1 \mathrm{M}$ \\
\hline
\end{tabular}

\section{Cost per Target}

The total estimated cost per target is the sum of the carrying charges on the $\$ 90 \mathrm{M}$ capital investment plus the annual operating cost divided by the annual target production. Assuming a constant dollar fixed charge rate of $10 \%$, the total annual cost of target production is $\$ 18.1 \mathrm{M}$, and the cost per target (based on $1.1 \times 10^{8}$ targets per year) is $16 \varnothing$. This is about a factor of two below the goal of $30 \notin$ per target and represents about $6 \%$ of the assumed $5 \phi / \mathrm{kW}$ h cost of electricity.

\section{Cost Scaling}

In the previous section, costs were estimated for the reference case design of a target factory producing targets at $5 \mathrm{~Hz}$ for a $1-\mathrm{GW}_{\mathrm{e}}$ power plant. In this section, we examine the variations in cost as a function of rep-rate and plant capacity. Table IX shows the cost scaling for the capital cost components listed in Table VIII. The capsule production and hohlraum production and assembly costs are assumed to scale with the production rate and are independent of the target yield. The scaling exponent is 0.7 , which is typical for rep-rate dependent manufacturing processes. The costs of DT fill equipment, cryogenics, and the building premium are assumed to scale with the power plant capacity $\left(\mathrm{GW}_{\mathrm{e}}\right)$, which is proportional to the fusion power or the product of rep-rate and yield. The $2 / 3$ scaling exponent is indicative of a volumetric cost scaling for these components. The cost of robotics is taken as a constant. Operating costs are taken as proportional to the capital costs, which implies that the manpower and supplies and expenses scale directly with the TCI. 
The resulting cost scaling formula is

$$
\mathrm{TCI}=\$ 90 \mathrm{M}\left[0.14+0.73\left(\frac{\text { Rep-rate }}{5 \mathrm{~Hz}}\right)^{0.7}+0.13\left(\frac{\text { Net Power }}{1 \mathrm{GWe}}\right)^{0.67}\right] .
$$

The first term in the square bracket is the fraction of the total cost for robotics, i.e.,

$\$ 12.6 \mathrm{M} / \$ 90 \mathrm{M}=0.14$ (see Table IX for cost fractions). The second term, which depends on reprate, is the sum of capsule and hohlraum production cost fractions $(0.70+0.03)$. The final term, which scales with power, is the sum of DT-fill, cryogenics and building premium cost fractions $(0.03+0.04+0.06)$.

Table IX. Cost Scaling for Components of Target Factory

\begin{tabular}{|l|c|c|}
\hline \multicolumn{1}{|c|}{ Component } & $\begin{array}{c}\text { Fraction of total cost at } \\
\mathbf{5} \mathbf{~ H z} \text { and } \mathbf{~} \mathbf{G W}_{\mathbf{e}}\end{array}$ & Cost Scaling \\
\hline Capsule Production & 0.70 & rep-rate $^{0.7}$ \\
\hline Hohlraum Production \& Assembly & 0.03 & rep-rate $^{0.7}$ \\
\hline DT Fill & 0.03 & power $^{0.67}$ \\
\hline Robotics & 0.14 & constant $^{0}$ \\
\hline Cryogenics & 0.04 & power $^{0.67}$ \\
\hline Building Premium & 0.06 & power $^{0.67}$ \\
\hline
\end{tabular}

Figure 7 compares the cost per target with the goal of $0.5 \phi / \mathrm{kW}$ h (10\% of the assumed $\mathrm{COE}$ ) for two different size power plants, $1 \mathrm{GW}_{\mathrm{e}}$ and $0.5 \mathrm{GW}_{\mathrm{e}}$. At $1 \mathrm{GW}_{\mathrm{e}}$, the cost per target is less than the cost goal over the entire range of rep-rates $1-10 \mathrm{~Hz}$. At $0.5 \mathrm{GW}_{\mathrm{e}}$, the estimated target cost exceeds the cost goal for rep-rates greater than $4 \mathrm{~Hz}$. Note however, that the COE for a $0.5-\mathrm{GW}_{\mathrm{e}}$ plant will be higher than for a $1 \mathrm{GW}_{\mathrm{e}}$ plant; for Osiris, the $\mathrm{COE}$ at $0.5 \mathrm{GW}_{\mathrm{e}}$ was $\sim 8.5 \phi / \mathrm{kW}_{\mathrm{e}}$ (at $5 \mathrm{~Hz}$ ) compared to $5.7 \mathrm{q} / \mathrm{kW}_{\mathrm{e}}$ h at $1.0 \mathrm{GW}_{\mathrm{e}}$.

\section{Conclusions}

A conceptual description of an automated target factory has been presented. All the process steps are based on techniques that have been demonstrated in the laboratory for production of single targets at small scale. Scale-up to power-plant-size targets, operation at a high production rate, and operating in an automated facility without significant human manipulation are all major development issues for the target factory. Nonetheless, we have estimated the cost based on the projected cost of the major components and cost estimating formula used in the chemical engineering industry. Based on these estimates (given in 1990 
dollars), we find that the cost per target ranges from about $27 \notin$ at $2 \mathrm{~Hz}$ down to about $12 \not$ at $10 \mathrm{~Hz}$. The target cost is relatively insensitive to the plant power over the range we examined $\left(0.5\right.$ to $\left.1.0 \mathrm{GW}_{\mathrm{e}}\right)$, differing by less than $1 \notin$ at $5 \mathrm{~Hz}$, for example. At $1 \mathrm{GW}_{\mathrm{e}}$, the cost of targets production is significantly less than $10 \%$ of the assumed $5 \notin / \mathrm{kW}_{\mathrm{e}} \mathrm{h}$ COE from the IFE power plant. The cost fraction increases with decreasing power plant size; at $0.5 \mathrm{GWe}$, the cost of targets will be less than $10 \%$ of the assumed COE if the rep-rate is less than $4 \mathrm{~Hz}$, but it reaches $\sim 17 \%$ of the COE at $10 \mathrm{~Hz}$.

We find that the capsule fabrication, which is the most precise component, dominates the factory cost. Also, the use of diffusion filling leads to a rather large $(4 \mathrm{~kg})$ tritium inventory. These are two areas in which further R\&D could pay large dividends.

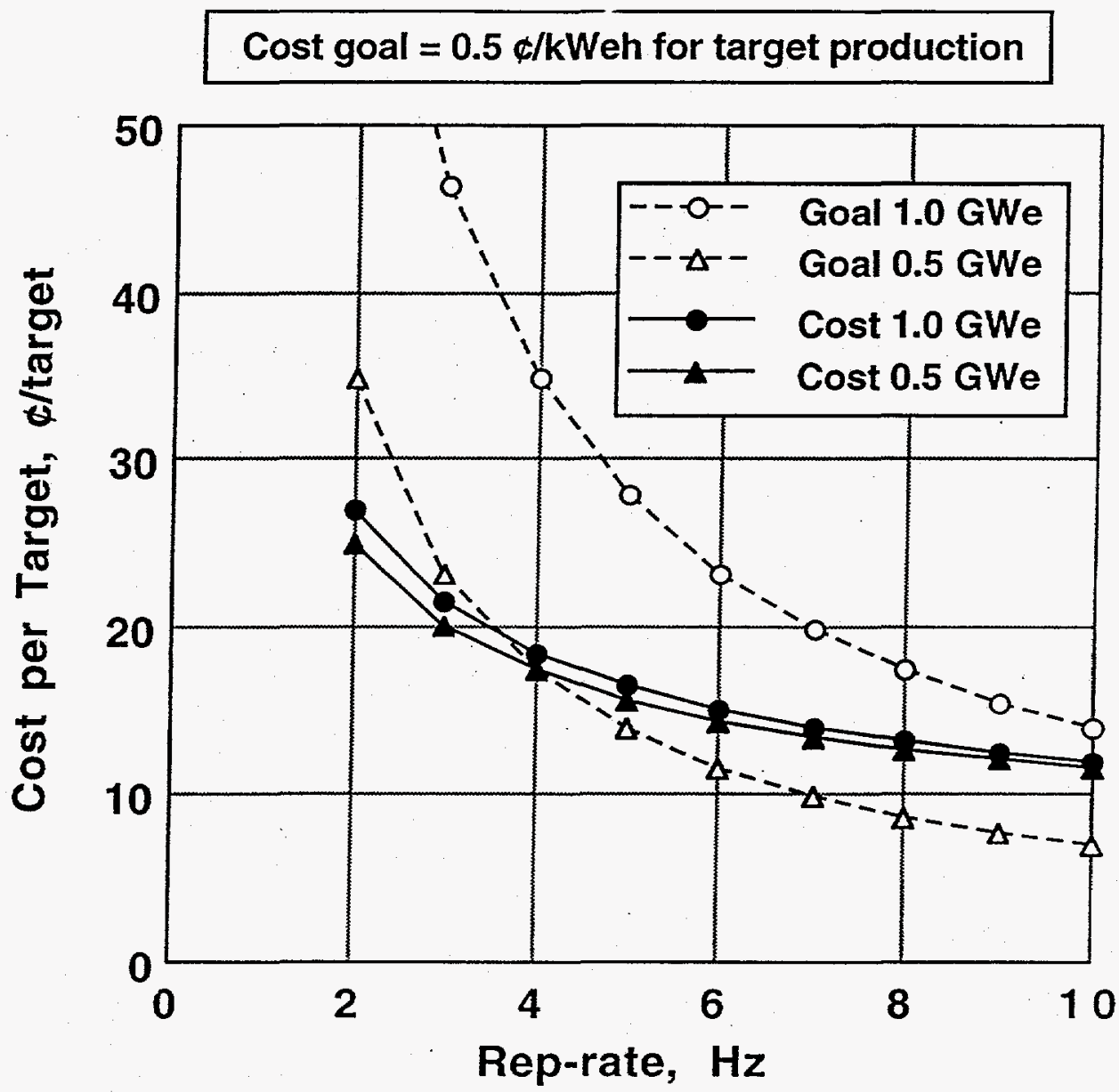

Figure 7. Target cost versus rep-rate for different size power plants compared to a goal of $0.5 \phi / \mathrm{kW}_{\mathrm{e}} \mathrm{h}\left(=10 \%\right.$ of the assumed COE of $\left.5 \phi / \mathrm{kW}_{\mathrm{e}} \mathrm{h}\right)$. 


\section{References}

1. J.H. Pitts, "Cascade: A Centrifugal-Action Solid Breeder Reaction Chamber," Nuclear Technol./Fusion, 4, 967 (1983). Also see J.H. Pitts et al., "The Cascade Inertial Confinement Fusion Reactor Concept," UCRL-LR-104546 (Dec. 1993).

2. R.W. Moir et al., "HYLIFE-II: A Molten-Salt Inertial Fusion Energy Power Plant Design Final Report," Fusion Technol., 25, 5 (1994).

3. W.R. Meier et al., "OSIRIS and SOMBRERO Inertial Fusion Power Plant Designs," DOE/ER/54100-1, WJSA-92-01, W. J. Schafer Associates, Inc., Livermore, CA, (March 1992). Also see W.R. Meier, "Osiris and SOMBRERO Inertial Fusion Power Plant Designs-Summary, Conclusions, and Recommendations," Fusion Eng. and Design, 25, 145 (1994).

4. L.M. Waganer et al., "Inertial Fusion Energy Reactor Studies: Prometheus-L and Prometheus-H," DOE/ER-54101, MDC 92E0008, McDonnell Douglas Aerospace, St. Louis, MO (March 1992).

5. B. Badger et al., "HIBALL - A Conceptual Heavy Ion Beam Driven Fusion Reactor Study," University of Wisconsin Fusion Technology Institute Report UWFDM-450 and KfK-3202 (June 1981).

6. I.N. Sviatoslavsky et al., "A Near Symmetric Illuminated Direct Drive Laser Fusion Power Reactor - SIRIUS-P," Fusion Technol., 26, 868 (1994).

7. G.L. Kulcinski et al., "Evolution of Light Ion Driven Fusion Power Plants Leading to the LIBRA-SP Design, “ Fusion Technol., 26, 849 (1994).

8. C.D. Hendricks, W.L. Johnson, "Power Plant Production of Inertial Confinement Fusion Targets," UCRL-52539, LLNL, Livermore, CA (Feb. 1979).

9. .J.W. Sherohman, W.R. Meier, "A Parametric Study of a Target Factory for Laser Fusion," Proc. ANS Topical Mtg. on the Technology of Controlled Nuclear Fusion, King of Prussia, PA (Oct. 14, 1980).

10. J.H. Pendergrass, D.B. Harris, D.J. Dudziak, "Heavy Ion Fusion Target Cost Model," Fusion Technol., 13, 375 (1988).

11. M.J. Monsler (author) Section 3.3, "Target Fabrication and Positioning," W.J. Hogan (editor), Energy from Inertial Fusion, IAEA Book to be published.

12. M.J. Monsler, W.R Meier, "Automated Target Production for Inertial Fusion Energy," Fusion Technol., 26, 873 (1994).

13. D.D.-M. Ho, J.A. Harte, M. Tabak, "Radiation-Driven Targets for Heavy-Ion Fusion," Proc. of I5th IAEA Int. Conf. on Plasma Phys. and Controlled Fusion Research (Seville, Spain, Sept. 6 to Oct. 1, 1994) IAEA-CN-60/B-P-13 (1994). 
14. D. Nelson, "Production of Polymer Shells by Controlled-Mass Microencapsulation," Proc. 9th Target Fabrication Specialists Mtg., Monterey, CA., July 6-8, 1993, LLNL, Livermore, CA (July 1993).

15. J.K Hoffer, L.R. Foreman, E.R. Mapoles, J.D. Simpson, "Forming a 'Perfectly' Uniform Shell of Solid DT Fusion Fuel by the Beta-Layering Process," Proc. 14th International Conf. of Physics and Controlled Nuclear Fusion Research, Wurzburg, Germany, Oct. 1992, IAEA-CN-56/G-3-4 (1992).

16. R.W. Moir, "Suggestions for Future Target Design Work to Improve Practicality and Lower Cost," LLNL Internal Memorandum (Dec. 6, 1994).

17. M.S. Peters, K-D. Timmerhaus, "Plant Design and Economics for Chemical Engineers," McGraw Hill (1968).

18. Private communication, Ray Tobin, CEO, Real Seal Corporation (1990). John Brown Plastics Machinery, Continuous Vacuum Forming Machine, similar to model 2530 BT. 